\title{
Dosimetric Characterizations of Megavoltage Therapeutic Photon Beam
}

\author{
Md. Abdullah Al Mashud ${ }^{1^{*}}$ and M. Jahangir Alam ${ }^{2}$ \\ ${ }^{1}$ Department of Electrical and Electronic Engineering, Islamic University, Kushtia-7003, Bangladesh. \\ ${ }^{2}$ Medical Physics Division, Department of Radiation Oncology, Ahsania Mission Cancer and \\ General Hospital, Uttara, Dhaka, Bangladesh.
}

\begin{abstract}
Authors' contributions
This work was carried out in collaboration between both authors. Both authors read and approved the final manuscript.

Article Information

DOI: $10.9734 / A R R B / 2020 / v 35 i 930280$

Editor(s):

(1) Dr. Viduranga Y. Waisundara, Australian College of Business and Technology, Sri Lanka.

Reviewers:

(1) Saloni Shah, Bai Jerbai Wadia Hospital for Children, India. (2) İsmail Faruk Durmuş, Nişantaşı University and New Century University Hospital Gaziosmanpasa, Turkey.

(3) Partizan Malkaj, Polytechnic University of Tirana (UPT), Albania. Complete Peer review History: http://www.sdiarticle4.com/review-history/59876
\end{abstract}

Original Research Article

Received 05 June 2020

Accepted 10 August 2020

Published 02 September 2020

\begin{abstract}
This paper presents the dosimetric parameters characterizations of a megavoltage therapeutic photon beam. The main focus of this study is to investigate and analyze the parameters of percentage depth dose (PDD) and tissue maximum ratio (TMR) due to the importance of treatment system. The depth dose characteristics of $6 \mathrm{MV}$ photon beam for different field sizes in water phantom has been measured, analyzed and found a robustness results. The results revealed that the depth dose variation from $0.067 \%$ to $1.812 \%$ and the TMR values varies from $0.501 \%$ to $2.111 \%$. It seems the measured dosimetric quantities are clinically relevant for different field sizes and depths.
\end{abstract}

Keywords: PDD; TMR; accuracy; LINAC; photon beam.

\section{INTRODUCTION}

Radiotherapy is applied with various techniques and equipment for local treatment of cancer all over the world. Most often, the equipment is used in radiotherapy to the patient irradiation are linear accelerators (LINAC) which delivers beam of $X$ rays in the range 4-30 MeV [1]. The exact 
determinations of radiotherapy parameters describing depth dose characteristics of photon beams are so essential for treatment planning [24]. To measure dosimetric parameters of radiotherapy homogeneous water phantom or equal medium should be used properly [1]. The dose distribution measurement in real patient is impossible [5]. So, all measurements have estimated by using water phantom for calculating the dose that can be applied to the actual patient for treating cancerous tissue [6-8]. The measurement of absorbed dose in the body depends on many factors (Photon energy, source to surface distance (SSD), field size and depth) [3]. During the treatment on radiotherapy it can be observed that the chance of cure may be decreased or increased in chance of irreversible damage 2 to 3 times if the dose delivery to the patient is decreased or increased by $10-15 \%$ [9]. In this case, the better recommendation of accuracy is $\pm 5 \%$ in delivery of dose in radiotherapy as prescribed by ICRU [10] but the tolerance of $3.5 \%$ has been advised [11] that can be gained by tracking a strict quality assurance program [12]. In the quality treatment, the existing approaches use basically two setups (i) SSD and (ii) iso-centric to calculate the radio therapeutic dose for patients [13].

In the existing state-of-the-art techniques: the SSD setup by using $80 \mathrm{~cm}$ Source to Surface Distance (SSD) for PDD measurements and isocentric setup by using $80 \mathrm{~cm}$ Source to Axis Distance (SAD) for TMR measurements. These two setups are complex since the human body is inhomogeneous and different organs are located at different positions of the body also it needs more times.

To minimize the complexity of machine setup and save time for measuring the values of PDD and TMR for several clinical field sizes, this paper proposed a single setup by using $90 \mathrm{~cm}$ Source to Surface Distance (SSD) as shown in Fig. 1.

\section{MATERIALS AND METHODS}

The Elekta Senergy Platform of 6MV photon beam and a PTW MP3-M water tank (PTW, Freiburg, Germany) with a scanning range of 50 $\mathrm{cm} \times 50 \mathrm{~cm} \times 40 \mathrm{~cm}$ is used in this work. Although various types of materials' phantoms are available recently but the water phantom is recommended for measurement due to the equivalent density of human tissue [14]. The PDD and TMR measurements have carried out along the CAX by using $0.125 \mathrm{cc}$ active volume of semiflex (31010) ion chamber. Farmer type chamber of $0.6 \mathrm{cc}$ (SN009016) is applied as reference. The PDD data have measured at a source-to-surface distance (SSD) of $90 \mathrm{~cm}$ for $10 \times 10 \mathrm{~cm}^{2}$ field size for various distances and also PDD have measured at $10 \mathrm{~cm}$ depth for square field sizes $-4 \mathrm{~cm}, 5 \mathrm{~cm}, 7 \mathrm{~cm}, 10 \mathrm{~cm}, 15$ $\mathrm{cm}, 20 \mathrm{~cm}, 30 \mathrm{~cm}$ and $40 \mathrm{~cm}$. The TMR values are calculated from the measured depth dose. All measurements have made keeping both the gantry and collimator angles of the unit at 0 degrees [5] by using protocol of International Atomic Energy Agency (IAEA) TRS-398 [15]. The proposed experimental setup is shown in Fig. 1.

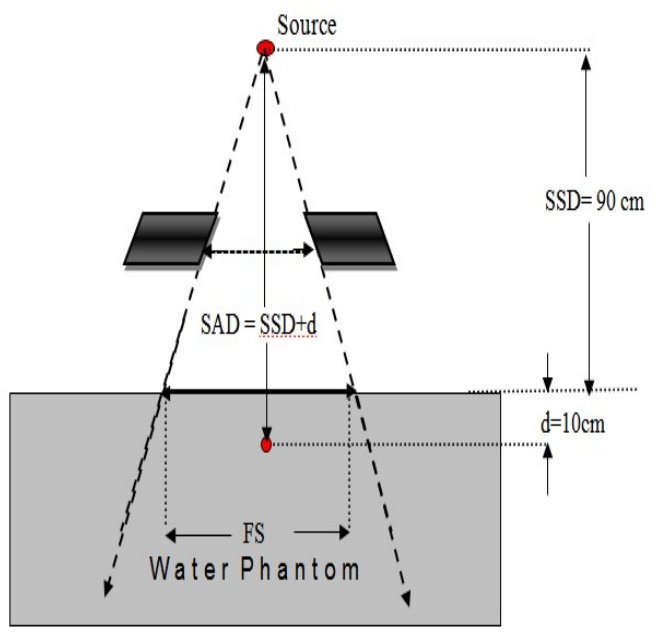

Fig. 1. The proposed SSD setup for dosimetric parameters measurements

The dosimetric data have measured by using the proposed setup and evaluated by MEPHYSTONavigation software at several depths and formulated for different depths with some rational step size [16]. The ratios of each of these readings on various depths and field sizes with point of maximum doses $(1.5 \mathrm{~cm}$ for $6 \mathrm{MV}$ photon) are build PDD and TMR values by using the equation (1) and equation (2) respectively.

$$
\mathrm{PDD}=\frac{\text { Dose at any depth }}{\text { Dose at } r_{f} \text { depth }\left(d_{10}\right)} \times 100
$$

Where $r_{f}$ depth $\left(d_{10}\right)$ is the dose at $10 \mathrm{~cm}$ depth

$$
\mathrm{TMR}=\frac{\text { Dose at any depth }}{\text { Dose at } D_{\max }}
$$

Where, the $D_{\max }$ for $4 \mathrm{MV}, 6 \mathrm{MV}$ and $15 \mathrm{MV}$ are $1.2 \mathrm{~cm}, 1.6 \mathrm{~cm}$ and $2.7 \mathrm{~cm}$ respectively. 


\section{RESULTS}

The characteristics of dose of photon beams can be assessed by its reduction with respect to its initial intensity in any medium. The decline in the beam intensity is observed owing to the attenuation of beam while entering the photon beam in the medium [3].

\subsection{Percent Depth Dose (PDD)}

The PDD have calculated by using equation (1) with $90 \mathrm{~cm}$ SSD on water surface. The PDD value is tabulated in Table 1 and compared with standard published value [2]. The value has measured for a fixed $10 \mathrm{~cm} \times 10 \mathrm{~cm}$ field size with variation of distance and normalized to $D_{\text {max }}$. The graphical representation of PDD in various distances is shown in Fig. 2(a). It indicates that the PDD values have decreased with depth. Also the PDD value has calculated for different field sizes at a depth in water of
$10 \mathrm{~cm}$ and the value is tabulated in Table 2 . The comparative study with standard data is observed in Fig. 2(b). If field sizes increase then the PDD value increase.

\subsection{Tissue Maximum Ratio (TMR)}

The TMR values have calculated by using equation (2) from the depth dose profile. The TMR values are tabulated in Table 3 and compared with standard published value BJR 25. The value has measured for a fixed $10 \mathrm{~cm} \times 10 \mathrm{~cm}$ field size with variation of distances in water. The graphical representations of TMR at various distance is observed in Fig. 3(a). It indicates that the TMR value decreases while increasing depth. And also the TMR value has calculated for various field sizes at the depth in water of $10 \mathrm{~cm}$ and the value is tabulated in Table 4. Fig. 3(b) shows the graphical representations of the comparative study. It indicates that the TMR value increases while the field size increases.

Table 1. Comparison of PDD data at various depths between proposed approach and BJR 25 published data [2] of 6MV Photon beam

\begin{tabular}{lllllll}
\hline Sr. No. & $\begin{array}{l}\text { Depth } \\
\text { (cm) }\end{array}$ & $\begin{array}{l}\text { Proposed Approach } \\
\text { (\%) }\end{array}$ & $\begin{array}{l}\text { BJR 25 } \\
\text { (\%) }\end{array}$ & \% Variation & $\begin{array}{l}\mathbf{R}^{2} \text { Value } \\
\text { (Proposed } \\
\text { Approach) }\end{array}$ & $\begin{array}{c}\mathbf{R}^{2} \text { Value } \\
\text { (BJR 25) }\end{array}$ \\
\hline 1. & 1.5 & 100.00 & 100.00 & 0.000 & & \\
2. & 2 & 99.30 & 98.80 & -0.506 & & \\
3. & 3 & 95.10 & 95.10 & 0.000 & & \\
4. & 4 & 89.80 & 91.00 & 1.319 & & \\
5. & 5 & 86.40 & 86.90 & 0.575 & & \\
6. & 6 & 81.30 & 82.80 & 1.812 & & \\
7. & 7 & 77.90 & 78.80 & 1.142 & 0.9997 & \\
8. & 8 & 74.10 & 74.90 & 1.068 & & \\
9. & 9 & 70.00 & 71.10 & 1.547 & & \\
10. & 10 & 66.60 & 67.50 & 1.333 & & \\
11. & 15 & 51.30 & 51.70 & 0.774 & & \\
12. & 20 & 38.90 & 39.30 & 1.018 & & \\
13. & 25 & 29.92 & 29.90 & -0.067 & & \\
14. & 30 & 22.90 & 22.80 & -0.439 & & \\
\hline
\end{tabular}

Table 2. Comparison of PDD data for various field sizes at $10 \mathrm{~cm}$ depth between proposed approach and BJR 25 published data [2] of 6MV Photon beam

\begin{tabular}{lllllll}
\hline Sr. No. & $\begin{array}{l}\text { Field Size } \\
\left(\mathbf{c m}^{2}\right)\end{array}$ & $\begin{array}{l}\text { Proposed Approach } \\
(\%)\end{array}$ & $\begin{array}{l}\text { BJR 25 } \\
(\%)\end{array}$ & \% Variation & $\begin{array}{l}\mathbf{R}^{2} \text { Value } \\
\text { (Proposed } \\
\text { Approach) }\end{array}$ & $\begin{array}{l}\mathbf{R}^{2} \text { Value } \\
\text { (BJR 25) }\end{array}$ \\
\hline 1. & $4 \times 4$ & 62.58 & 63.0 & 0.667 & & \\
2. & $5 \times 5$ & 63.55 & 64.0 & 0.703 & & \\
3. & $7 \times 7$ & 64.97 & 65.7 & 1.111 & & \\
4. & $10 \times 10$ & 66.97 & 67.5 & 0.785 & 0.9997 & 0.9999 \\
5. & $15 \times 15$ & 68.90 & 69.3 & 0.577 & & \\
6. & $20 \times 20$ & 69.80 & 70.4 & 0.852 & & \\
7. & $30 \times 30$ & 70.93 & 71.7 & 1.074 & & \\
8. & $40 \times 40$ & 71.90 & 72.5 & 0.828 & & \\
\hline
\end{tabular}




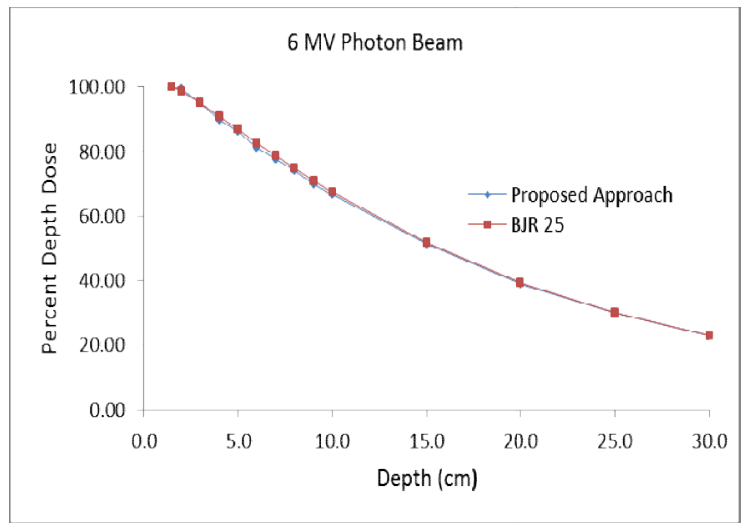

(a)

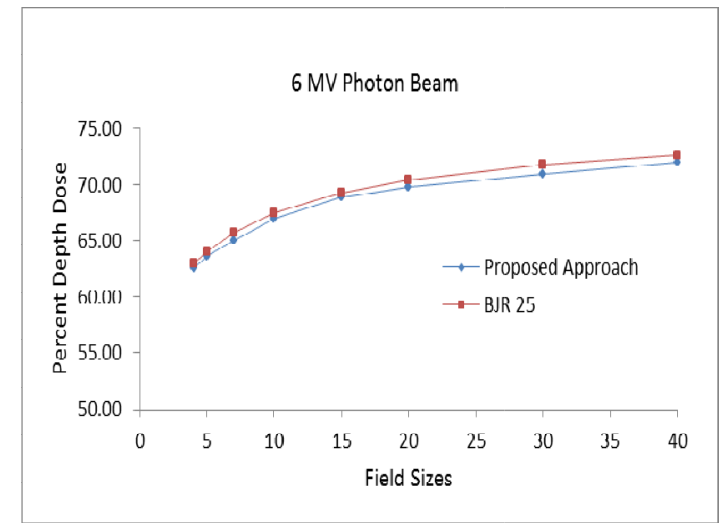

(b)

Fig. 2. Comparison of PDD data in water phantom (a) against depth for $10 \times 10 \mathrm{~cm}^{2}$ field size, (b) against field sizes at $10 \mathrm{~cm}$ depth with published data of BJR 25 [2]

Table 3. Comparison of TMR data at various depths between proposed approach and BJR 25 published data [2] of 6MV Photon beam

\begin{tabular}{lllllll}
\hline Sr. No. & Depth (cm) & $\begin{array}{l}\text { Proposed } \\
\text { Approach } \\
\text { (\%) }\end{array}$ & $\begin{array}{l}\text { BJR 25 } \\
\text { (\%) }\end{array}$ & \% Variation & $\begin{array}{l}\mathbf{R}^{2} \text { Value } \\
\text { (Proposed } \\
\text { Approach) }\end{array}$ & $\begin{array}{l}\mathbf{R}^{2} \text { Value } \\
\text { (BJR 25) }\end{array}$ \\
\hline 1. & 1.5 & 1.000 & 1.000 & 0.0000 & & \\
2. & 2.0 & 0.993 & 0.998 & 0.5010 & & \\
3. & 3.0 & 0.971 & 0.979 & 0.8172 & & \\
4. & 4.0 & 0.948 & 0.954 & 0.6289 & & \\
5. & 5.0 & 0.918 & 0.928 & 1.0776 & & \\
6. & 6.0 & 0.881 & 0.900 & 2.1111 & 0.9998 & \\
7. & 7.0 & 0.862 & 0.871 & 1.0333 & & \\
8. & 8.0 & 0.837 & 0.843 & 0.7117 & & \\
9. & 9.0 & 0.806 & 0.814 & 0.9828 & & \\
10. & 10.0 & 0.781 & 0.786 & 0.6361 & & \\
11. & 15.0 & 0.645 & 0.650 & 0.7692 & & \\
12. & 20.0 & 0.528 & 0.532 & 0.7519 & & \\
13. & 25.0 & 0.439 & 0.433 & -1.3857 & & \\
14. & 30.0 & 0.358 & 0.352 & -1.7045 & & \\
\hline
\end{tabular}

Table 4. Comparison of TMR data for various field sizes at $10 \mathrm{~cm}$ depth between proposed approach and BJR 25 published data [2] of 6MV Photon beam

\begin{tabular}{lllllll}
\hline Sr. No. & $\begin{array}{l}\text { Field Size } \\
\left(\mathbf{c m}^{2}\right)\end{array}$ & $\begin{array}{l}\text { Proposed } \\
\text { Approach } \\
(\%)\end{array}$ & $\begin{array}{l}\text { BJR 25 } \\
(\%)\end{array}$ & \% Variation & $\begin{array}{l}\mathbf{R}^{2} \text { Value } \\
\text { (Proposed } \\
\text { Approach) }\end{array}$ & $\begin{array}{l}\mathbf{R}^{2} \text { Value } \\
\text { (BJR 25) }\end{array}$ \\
\hline 1. & $4 \times 4$ & 0.740 & 0.735 & -0.680 & & \\
2. & $5 \times 5$ & 0.753 & 0.745 & -1.074 & & \\
3. & $7 \times 7$ & 0.780 & 0.765 & -1.961 & & \\
4. & $10 \times 10$ & 0.799 & 0.786 & -1.654 & & \\
5. & $15 \times 15$ & 0.820 & 0.808 & -1.485 & 0.9992 & 0.9999 \\
6. & $20 \times 20$ & 0.830 & 0.82 & -1.220 & & \\
7. & $30 \times 30$ & 0.850 & 0.837 & -1.553 & & \\
8. & $40 \times 40$ & 0.861 & 0.848 & -1.533 & & \\
\hline
\end{tabular}




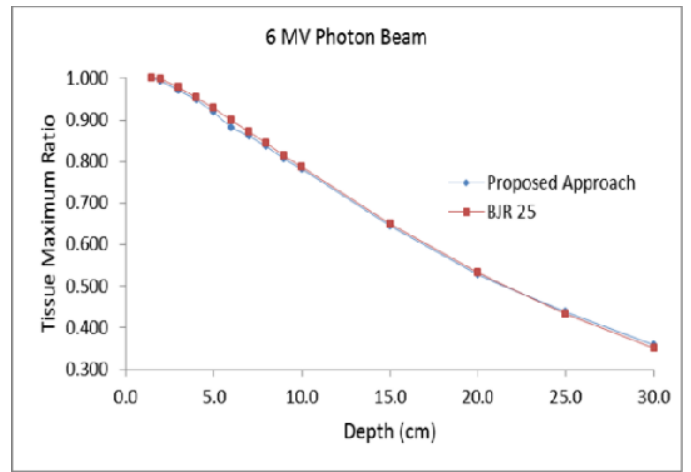

(a)

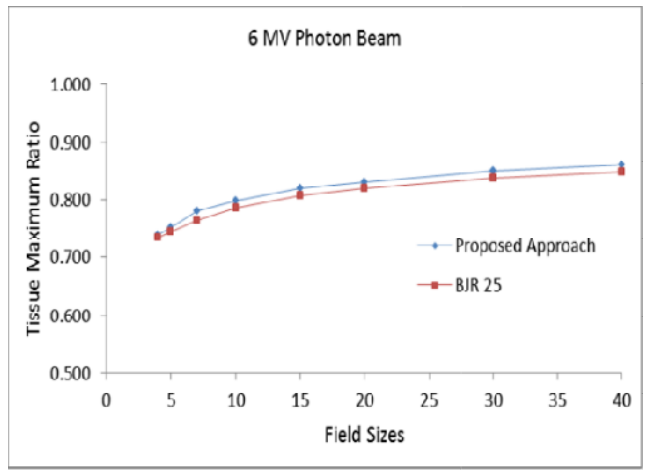

(b)

Fig. 3. Comparison of TMR data in water phantom (a) against depth for $10 \times 10 \mathrm{~cm}^{2}$ field size, (b) against field sizes at $10 \mathrm{~cm}$ depth with published data of BJR 25 [2]

From the above analysis and discussion it indicates that the PDD and TMR for 6MV photon beam for $10 \mathrm{~cm} \times 10 \mathrm{~cm}$ field size at the different depths shows variations from $0.067 \%$ to $1.812 \%$ $\left(R^{2}=0.9997\right)$ and $0.501 \%$ to $2.111 \%\left(R^{2}=\right.$ $0.9998)$ respectively. It also shows for different field sizes at $10 \mathrm{~cm}$ depth the variations from $0.667 \%$ to $1.111 \%\left(R^{2}=0.9997\right)$ and $0.680 \%$ to $1.961 \%\left(R^{2}=0.9992\right)$ for PDD and TMR respectively. These results shows an optimistic assign with BJR $25\left(R^{2}=0.9999\right)$.

\section{DISCUSSION}

Dosimetric accuracy and good planning are very essential for actual delivery of radiation to the cancerous tissues [12]. Many a researcher have worked and performed on the characteristics of various $x$-ray beams $[7,8,14,17-19]$ by using two setups. The main focus of this research is that all measurements have carried out by using one setup. The PDD values are explained by Cakir T. et, al [20] that reports the \%age variation of 0.02 to $3.69 \%$. The TMRs value with \%age variation of 0.101 to $2.49 \%$ was reported by Akinlad-e B.I. et, al. [21]. The proposed study carried out \%age variations of PDD and TMR values are so well sign for $10 \mathrm{~cm} \times 10 \mathrm{~cm}$ field size. For several field sizes the \%age variation for PDD and TMR values are within $2 \%$. These results show less $\%$ age variation than the previous cases $[20,21]$.

\section{CONCLUSION}

This research proposed a technique which measures the PDD and TMR values by using a single setup. The proposed technique has examined properly with several clinical field sizes. Since, the proposed technique saves enough time. This procedure will be quite beneficial for the treatment modalities of cancer patients.

\section{COMPETING INTERESTS}

Authors have declared that no competing interests exist.

\section{REFERENCES}

1. Praveenkumar RD, Santosh KP, Augustine A. Estimation of inhomogenity correction factors for a Co-60 beam using monte carlo simulation. Journal of Cancer Research and Therapeutics. 2011;7(3): 308-313.

2. Jordan TJ. Megavoltage X-ray BEAMS: 250 MV. Br J Radiol Suppl. 1996;25:62-109.

3. Buzdar SA, Rao MA, Nazir A. an analysis of depth dose characteristics of photon in water. Journal of Ayub Medical College. 2009;21(4):41-45.

4. Chen L, Chen LX, Sun $H Q$, Huang SM, Sun WZ, Gao XW, Deng XW. Measurements and comparisons for data of small beams of linear accelerators. Chinese Journal of Cancer. 2009;28(3): 272-276.

5. Memon SA, Cheema AA, Laghari NA, Mangi FH. Dose measurement of cobalt-60 radiotherapy beams in treatment fields. Journal of Ayub Medical College. 2014; 26(3):279-282.

6. Ravikumar M, Ravichandran R. Dose measurements in the build-up region for the photon beams from Clinac-1800 dual energy medical linear accelerator. Strahlentherapie and Onkologie. 2002; 176(5):223-228.

7. Xhafa B, Mulaj T, Hodolli G, Nafezi G. Dose distribution of photon beam by 
siemens linear accelerator. International Journal of Medical Physics, Clinical Engineering and Radiation Oncology. 2014;3:67-70.

8. Birgani MJT, Karbalaee SM. Calculation of analytical expressions for measured percentage depth dose data in megavoltage photon therapy. Iranian Red Crescent Medical Journal. 2009;11(2):140144.

9. Yeo IJ, Wang CK, Burch SE. A filtration method for improving film dosimetry in photon radiation therapy. Medical Physics. 1997;24:1943-1953.

10. Shalek RJ. Determination of absorb dose in a patient irradiated by beams of $X$ or Gamma rays in radiotherapy procedures. 1977; 4(5):461.

11. Mijnheer BJ, Battermann JJ, Wambersie A. What degree of accuracy is required and can be achieved in photon and neutron therapy? Radiotherapy and Oncology. 1987;8(3):237- 252.

12. Lanchun L. Dose calculation algorithms in external beam photon radiation therapy. International Journal of Cancer Therapy and Oncology. 2013;1(2):01025.

13. Sajjad AM, Naeem AL, Fayaz HM, Fayaz A, Muhammad MH, Sehar P, Naseema J, Arshia A. Analysis and verification of percent depth dose and tissue maximum ratio for co-60 gamma ray beam. World Applied Sciences Journal. 2015;33(1):109113.

14. Aukett RJ, Burns JE, Greener AG, Harrison RM, Moretti C, Nahum AE, Rosser KE. Addendum to the IPEMB code of practice for the determination of absorbed dose for X-rays below $300 \mathrm{kV}$ generating potential $(0.035 \mathrm{mmAl}-4 \mathrm{~mm} \mathrm{Cu}$ HVL). Physics in Medicine and Biology. 2005;50(12):2739-2748.
15. Andreo $\mathrm{P}$, et al. Absorbed dose determination in external beam radiotherapy. An international code of practice for dosimetry based on standards of absorbed dose to water. Technical Report Series no. IAEA TRS-398; 2004.

16. Buzdar SA, Shamsi QA, Afzal M, Nazir A, Nizamani $\mathrm{AH}$, Gadhi MA. Verification of absorbed radiation dose for X-rays through Lagrange's interpolation method. Proceedings of the Pakistan Academy of Sciences. 2013;50(4):309-314.

17. Ismail M, Afzal M, Nadeem M, Rana AM, Amjad S, Buzdar SA. Evaluation of depth dose characteristics of superficial X-Rays machine using different $k V p$ and applicators diameter. Iranian Journal of Radiation Research. 2011;9(3): 159-166.

18. Isa M, Iqbal K, Ashraf MJ, Afzal M, Buzdar SA. Percentage discrepancies assessment between measured and calculated behaviour of percent depth dose in external beam radiotherapy. Pakistan Journal of Scientific and Industrial Research, Series A: Physical Sciences. 2014;57(2):59-62.

19. Kanokjiraporn S, Thongruang C. Computation of the percent depth dose tables and tissue maximum ratio (in Thai). Bulletin Of The Department of Medical Sciences. 1993;35(1):35-45.

20. Cakir T, Gur A, Arasoglu A. The comparison of absorbed dose measurements for water and artificial body fluid. Iranian Journal of Radiation Research. 2012;10(3-4):157-164.

21. Akinlade $\mathrm{BI}$, Oyekunle $\mathrm{EO}$, Adenipekun AA, Elumelu-Kupoluyi TN, Folasire AM. Dosimetric verification of Bhabhatron-II telecobalt unit at the university college hospital, Ibadan, Nigeria. Cancer Biology. 2014;4(2):22-29.

(c) 2020 Al Mashud and Alam; This is an Open Access article distributed under the terms of the Creative Commons Attribution License (http://creativecommons.org/licenses/by/4.0), which permits unrestricted use, distribution, and reproduction in any medium, provided the original work is properly cited.

Peer-review history:

The peer review history for this paper can be accessed here: http://www.sdiarticle4.com/review-history/59876 